\title{
O DESAFIO DIAGNÓSTICO DA DOENÇA INFLAMATÓRIA INTESTINAL NA PEDIATRIA: UM RELATO DE CASO
}

\section{Pôster}

Autores deste trabalho:

Mariana Aparecida Brunossi Moura Proença : Hospital Infantil Cândido Fontoura

Pedro Teles de Mendonça Neto: Hospital Infantil Cândido Fontoura

Maryana Beltrão de Carvalho: Hospital Infantil Cândido Fontoura

Rafaela Oliveira Tavares: Hospital Infantil Cândido Fontoura

Ingrid Lacerda Pessoa: Hospital Infantil Cândido Fontoura

João Pedro de Figueiredo Jordão Furtado de Mendonça: Hospital Infantil Cândido Fontoura

Lineke Gonçalves Dias: Hospital Infantil Cândido Fontoura

Andressa Clemente Mesquita: Hospital Infantil Cândido Fontoura

Área do Trabalho: Pediatria

Data da submissão:10/08/2018 às 12:38

\section{Justificativa}

As Doenças Inflamatórias Intestinais (DII) representam afecções crônicas idiopáticas, com fatores genéticos e ambientais envolvidos, levando a má regulação da imunidade intestinal. São doenças emergentes e crescentes, representadas pela Retocolite Ulcerativa Inespecífica (RCUI) e Doença de Crohn (DC). As DII são diagnosticadas na infância em $25 \%$ dos casos. .

Objetivo(s) Não se aplica. Método(s) Não se aplica.

\section{Resultado(s)}

V.B.C, 14 anos, masculino, estudante, natural e procedente de São Paulo. Referia dor, edema e hiperemia em pés e joelhos há 10 dias, associado a palidez, astenia, hematoquezia e lesões pustulosas na pele há 8 meses. Na admissão hospitalar encontrava-se hipocorado, emagrecido, com presença de pústulas em membros inferiores, artrite em joelhos, tornozelos e cotovelo esquerdo, hiperemia conjuntival esquerda e plicoma. Exames laboratoriais mostraram anemia ferropriva, VHS e ferritina elevadas. A colonoscopia revelou Pancolite erosiva com úlceras colônicas e reto apresentava numerosas lesões com mais de $5 \mathrm{~mm}$, profundas, recobertas de fibrina, também presentes em mucosa de colón ascendente, transverso e descendente. Ao Anatomopatológico detectado retite e colite crônica não especificada. Resultado de anticorpo contra o Saccharomyces cerevisiae (ASCA) IgA reagente e IgG não reagente. Levantado hipótese de $D C$ e feito tratamento com Sulfassalazina.

\section{Conclusão (ões)}

Na DC há inflamação transmural, que pode afetar desde a boca até o ânus, principalmente o delgado distal e cólon, como no caso em questão. As manifestações 
extra-intestinais seguem o padrão de doenças inflamatórias. O ASCA é apontado como possível marcador sorológico da doença e está presente na DC em cerca de $35 \%$ a $80 \%$ dos casos, auxiliando o diagnóstico inicial de colite indeterminada. Os aminossalicilatos são o tratamento inicial, posteriormente corticoides e biológicos. As DII estão em contínuo crescimento na população pediátrica, devendo o pediatra estar atento ao seu diagnóstico e instituição precoce do tratamento. 